\title{
SISTEM PENDUKUNG KEPUTUSAN PEMILIHAN ASURANSI JIWA MENGGUNAKAN METODE ANALYTIC HIERARCHY PROCESS DENGAN CRITERIUM DECISION PLUS
}

\author{
Imam Sunoto $^{1^{*}}$, Arif Susanto ${ }^{2}$ \\ 1,2Teknik Informatika,Fakultas Teknik, Universitas Indraprasta PGRI \\ Jl. Nangka 58C, Tanjung Barat, Jagakarsa - Jakarta Selatan 12530 \\ *E-mail: raidersimam@gmail.com
}

\begin{abstract}
ABSTRAK
Pengembangan bisnis asuransi di saat yang berkembang pesat, di mana ini bisa membuat bingung dalam menentukan calon pelanggan untuk memilih opsi asuransi yang sesuai dengan keinginan dan kebutuhan mereka. Asuransi jiwa adalah bisnis di jasa yang memberikan jaminan kepada pelanggan ketika mereka mengalami peristiwa yang beresiko hilang produktivitasnya menjadi keuangan. Namun, sebagian besar pelanggan benarbenar menyesal telah nasabah asuransi menjadi karena kurangnya pemahaman mereka untuk asuransi itu sendiri. sistem informasi berbasis komputer dapat digunakan dalam memecahkan masalah pengambilan keputusan sering disebut sistem pendukung keputusan yang dapat membantu setiap orang dalam pilihan masalah yang akan dihadapi. Metode ini dapat digunakan dalam pemilihan asuransi jiwa dinilai metode proses analisis dimana setiap alternatif akan dilakukan perengkingan untuk mendapatkan hasil terbaik. Dengan bantuan hasil akhir Criterium Decision Plus (CDP) 3.0 software sistem pemilahan dalam bentuk perusahaan asuransi jiwa yang digunakan sebagai alat dalam pengambilan keputusan untuk pelanggan potensial. sistem pendukung keputusan diharapkan dapat membantu calon pelanggan untuk memilih asuransi jiwa yang tepat dan sesuai dengan kebutuhan.
\end{abstract}

Kata kunci: Sistem Pendukung Keputusan, Asuransi Jiwa, Proses Hirarki Analisis

\begin{abstract}
Development of insurance business in the current rapidly evolving, where this can create confusion in determining the prospective customer to choose an insurance option that suits their wants and needs. Life insurance is a business in the services it provides assurance to its customers when they experience the events that are at risk of missing its productivity be financial. However, most customers are actually regret having become insurance customers due to their lack of understanding for insurance itself. Computer-based information systems can be used in solving the problem of decision-making is often called a decision support system that can help everyone in the choice of a problem that will be faced. The method can be used in the selection of life insurance is graded analysis process method wherein each alternative will be made perengkingan to obtain the best results. With the help of Criterium Decision Plus (CDP) 3.0 software end result sorting system in the form of a life insurance company that is used as a tool in decision making for potential customers. Decision support system is expected to help prospective customers to choose the right life insurance and in accordance with needs.
\end{abstract}

Keywords: Decision Support System, Life Insurance, Analytic Hierarchy Process 


\section{PENDAHULUAN}

Pada saat ini pertumbuhan usaha asuransi begitu pesat berkembang. Dengan begitu banyaknya program yang ditawarkan tentunya menjadi daya tarik bagi calon nasabah yang ingin menggunakan jasa asuransi. Produk asuransi yang ditawarkan pun bermacam mulai dari asuransi jiwa,kendaraan maupun asuransi terhadap properti ataupun bangunan. Untuk setiap calon nasabah program asuransi yang mereka butuhkan pastinya berbedabeda pula. Namun kebanyakan orang akhirnya menyesal setelah masuk asuransi dikarenakan mereka kurang memahami akan kebutuhan mereka didalam berasuransi,sehingga yang terjadi mereka menganggap asuransi itu tidak bermanfaat.

Dalam kehidupan sehari-hari, setiap manusia dihadapakan dengan masalah pengambilan keputusan yang bermacammacam. Dari keputusan yang mudah diambil, dan juga keputusan yang baru dapat diambil setelah dipertimbangkan segala macam aspek secara cermat, ada keputusan yang hasilnya hanya membawa konsekuensi bagi pihak yang mengambil keputusan tersebut, ada juga keputusan yang menyangkut nasib orang banyak,Sedangkan Sistem pendukung keputusan itu sendiri merupakan bagian dari sistem informasi berbasis komputer (termasuk sistem berbasis pengetahuan/manajemen pengetahuan) yang dipakai untuk mendukung pengambilan keputusan dalam suatu organisasi atau perusahaan.Dapat juga dikatakan sebagai sistem komputer yang mengolah data menjadi informasi untuk mengambil keputusan dari masalah semi-terstruktur yang spesifik.

Seiring dengan perkembangan teknologi informasi semakin bertambah pula kemampuan komputer dalam membantu menyelesaikan permasalahan diberbagai bidang, diantaranya sistem pendukung keputusan berbasis komputer. Sistem ini dirancang untuk membantu pengambil keputusan dalam memecahkan permasalahan yang dihadapi. Dalam memecahkan masalah seseorang mungkin harus membuat banyak keputusan, untuk menghindari dampak negatif atau pemanfaatan kesempatan, Jadi pengambilan keputusan dapat menentukan baik atau tidaknya suatu pilihan. Untuk itulah maka dibuat suatu aplikasi sistem pendukung keputusan dalam hal memilih asuransi jiwa, dimana dengan adanya sistem ini diharapkan dapat membantu calon nasabah agar tidak salah atau keliru dalam memilih asuransi jiwa.

\section{METODE PENELITIAN}

Metodologi terdiri atas tata cara untuk memperoleh data yang terkait. Untuk menghasilkan dan tercapainya tujuan dalam kegiatan ini, tentunya memerlukan data. Jenis data yang digunakan dalam kajian ini adalah data primer. Tahapan pengumpulan data/survey dalam penelitian ini meliputi pengumpulan data baik yang bersifat kualitatif maupun kuantitatif terhadap aspek aspek yang berhubungan dengan pemilihan asuransi sesuai dengan kriteria dan bobot yang dimiliki untuk perengkingan. Pengumpulan data yang akan dilakukan dalam survey ini meliputi data primer (wawancara dan kuesioner, data publikasi dan rujukan).

\section{LANDASAN TEORI Pengertian Sistem}

Sistem merupakan kumpulan elemen yang saling berkaitan yang bertanggung jawab memproses masukan, sehingga menghasilkan keluaran. Suatu sistem di dalam suatu organisasi mempertemukan kebutuhan pengolahan transaksi harian, mendukung operasi, bersifat manajerial,dan merupakan kegiatan strategi dari suatu organisasi, serta menyediakan laporanlaporan yang diperlukan oleh pihak luar.

Menurut Kusrini (2007) Istilah sistem sering kali digunakan untuk mewujudkan pengertian metode atau cara yang merupakan suatu himpunan unsur atau komponen yang saling berhubungan satu sama lainya yang membentuk suatu kesatuan yang utuh yang sedang berkaitan dan ketergantungan satu sama lainya untuk mencapai tujuan tertentu.

\section{Sistem Pendukung Keputusan}

Menurut Efraim (2005), Sistem Pendukung Keputusan sebagai Sekumpulan prosedur berbasis model untuk data pemrosesan dan penilaian guna membantu para manajer mengambil keputusan untuk sukses, sistem tersebut haruslah sederhana, cepat, mudah dikontrol, adaptif lengkap dengan isuisu penting, dan mudah berkomunikasi. 
Dari definisi tersebut, dapat diindikasikan empat karakteristik utama dari Sistem Pendukung Keputusan, yaitu:

1. Sistem Pendukung Keputusan menggabungkan data dan model menjadi satu bagian.

2. Sistem Pendukung Keputusan dirancang untuk membantu para manajer (pengambil keputusan) dalam proses pengambil keputusan dari masalah yang bersifat semi struktural (tidak terstruktur).

3. Sistem Pendukung Keputusan lebih cenderung dipandang sebagai penunjang penilaian manajer dan sama sekali bukan untuk menggantikannya.

4. Teknik Sistem Pengambil Keputusan dikembangkan untuk meningkatkan efektivitas dari pengambil keputusan.

Aplikasi dari Sistem Pengambil Keputusan baru dapat dikatakan berhasil atau bermanfaat, jika terdapat kondisi sebagai berikut:

1. Eksistensi dari basis data yang sangat besar, sehingga sulit mendayagunakannya.

2. Kepentingan adanya transformasi dan komputasi pada proses pencapaian keputusan.

3. Adanya keterbatasan waktu, baik dalam Penentuan hasil maupun dalam prosesnya.

4. Kepentingan akan penilaian atas pertimbangan akal sehat untuk menentukan dan mengetahui pokok permasalahan, serta pengembangan alternatif dan penilain solusi.

\section{Asuransi Jiwa}

Pengertian dari Asuransi Jiwa ialah pelimpahan resiko atas kerugian berupa keuangan oleh tertanggung kepada pihak penanggung. Resiko dari pihak tertanggung tersebut kepada penanggung bukanlah resiko atas hilangnya jiwa, akan tetapi merupakan kerugian berupa keuangan sebagai ganti rugi hilangnya jiwa seseorang atau karena dengan alasan umur sehingga tidak produktif.

Konsep resiko dari Asuransi Jiwa dilihat dari nilai ekonomi hidup seseorang kepada keluarganya serta seberapa besar penghasilannya. Apabila nilai ekonomi sebagai kepala keluarga hilang atauberkurang maka yang akan merasakan kehilangan adalah sanak keluarganya. Resiko dari kehilangan penghasilan yang harus di tanggung oleh keluarganya yang ditinggalkan.

Untuk mengurangi resiko tersebut pada zaman modern ini telah ditempuh satu cara dengan mengalihkan atau melimpahkan resiko tersebut kepada pihak lain, dalam hal ini Lembaga Asuransi Jiwa yang mengkhususkan usahanya dibidang ini sebagai profesinya. Pelimpahan resiko tersebut lebih popular disebut dengan membeli polis asuransi jiwa.

\section{Analytical Hierarchy Process}

Menurut Saaty, L. Thomas (1993), Proses Hirarki Analitik untuk mengorganisasikan informasi dan judgment dalam memilih alternatif yang paling disukai. Dengan menggunakan AHP, Suatu persoalan yang akan dipecahkan dalam suatu kerangka berpikir yang terorganisir, sehingga memungkinkan dapat diekspresikan untuk mengambil keputusan yang efektif atas persoalan tersebut. Persoalan yang kompleks dapat disederhanakan dan dipercepat proses pengambilan keputusannya.

Menurut Marimin dan Nurul (2011), Prinsip kerja AHP adalah penyederhanaan suatu persoalan kompleks yang tidak terstruktur, strategik dan dan dinamik menjadi bagian-bagiannya, serta menata dalam suatu hirarki. Kemudian tingkat kepentingan setiap variabel diberi nilai numerik secara subjektif tentang arti penting variabel tersebut secara relatif dibandingkan dengan variabel lain. Keuntungan penggunaan AHP, yaitu: kesatuan, kompleksitas, saling ketergantungan, penyusunan hierarki, pengukuran, konsistensi, sintesis, tawar-menawar, penilaian dan konsensus serta pengulangan proses. Ada tiga prinsip dalam memecahkan persoalan dengan metode AHP, yaitu: prinsip penyusunan hierarki, prinsip penetapan prioritas dan prinsip konsistensi logis. Dari pertimbangan tersebut kemudian diilakukan sintesa untuk menetapkan variabel yang memiliki prioritas tinggi dan berperan untuk mempengaruhi hasil pada sistem tersebut. Penyusunan skala kepentingan berpedoman pada tabel skala dasar sebagai berikut:

Tabel 1. Nilai dan definisi pendapat kualitatif dari skala perbandingan Saaty. 


\begin{tabular}{|c|l|}
\hline 1 & $\begin{array}{l}\text { Faktor vertikal sama penting dengan } \\
\text { Faktor horizontal }\end{array}$ \\
\hline 3 & $\begin{array}{l}\text { Faktor vertikal lebih penting dengan } \\
\text { Faktor horizontal }\end{array}$ \\
\hline 5 & $\begin{array}{l}\text { Faktor vertikal jelas lebih penting } \\
\text { dengan Faktor horizontal }\end{array}$ \\
\hline 7 & $\begin{array}{l}\text { Faktor vertikal sangat jelas lebih } \\
\text { penting dengan Faktor horizontal }\end{array}$ \\
\hline 9 & $\begin{array}{l}\text { Faktor vertikal mutlak lebih penting } \\
\text { dengan Faktor horizontal }\end{array}$ \\
\hline $2,4,6,8$ & $\begin{array}{l}\text { Apabila ragu-ragu antara dua nilai } \\
\text { elemen yang berdekatan }\end{array}$ \\
\hline $1 /(2-9)$ & Kebalikan dari keterangan nilai 2-9 \\
\hline
\end{tabular}

\section{Criterium Decision Plus}

Desktop software Criterium DecisionPlus 3.0 adalah sebuah Microsoft Windows ${ }^{\circledR}$ decision tool yang dapat membantu user dalam membuat keputusankeputusan yang kompleks dari alternatifalternatif yang ada dengan multi-kriteria. CDP dibuat oleh perusahaan InfoHarvest Inc. Pada gambar 1 ditunjukkan bahwa ukuran tidak menjadi masalah dalam CDP 3.0. CDP 3.0 juga dapat membantu dalam menyelesaikan permasalahan seperti: perekrutan pegawai baru, membuat keputusan dalam menginvestasikan modal, memprioritaskan anggaran yang tepat dan lain sebagainya.

\section{HASIL DAN PEMBAHASAN}

\section{Analisa Masalah}

Menentukan keputusan untuk pemilihan asuransi adalah sangat sulit, terkait banyaknya macam dan jenis asuransi jiwa saat ini dan mengingat banyaknya program yang ditawarkan oleh perusahaan asuransi yang dapat membingungkan para calon nasabah untuk menentukan pilihan mana yang tepat untuk mereka pilih dan tidak membuat mereka kecewa atau salah untuk memilih asuransi tersebut.

Dalam pemilihan Asuransi jiwa, diperlukan kriteria-kriteria dan bobot untuk melakukan perhitunganya sehingga akan didapat alternatif terbaik. Alternatif yang dimaksud adalah asuransi jiwa yang tepat untuk para calon nasabah

\section{Kriteria dan Bobot}

Dalam prosesnya diperlukan kriteriakriteria yang akan dijadikan bahan perhitungan pada proses perengkingan asuransi jiwa,
Kriteria yang menjadi bahan pertimbangan adalah sebagai berikut:

Tabel 2. Kriteria

\begin{tabular}{|c|c|}
\hline Kriteria & Keterangan \\
\hline$C_{1}$ & Premi \\
\hline$C_{2}$ & Pertanggungan \\
\hline$C_{3}$ & Jangka Premi \\
\hline$C_{4}$ & Santunan \\
\hline$C_{5}$ & Masa Pertanggungan \\
\hline
\end{tabular}

Dalam sebuah pemilihan asuransi jiwa yang akan dipilih, maka kriteria tersebut dimasukkan kedalam tabel sebagai berikut:

Keterangan:

$\mathrm{C}_{1}=$ Dalam ribu

$\mathrm{C}_{2}=$ Dalam Juta

$\mathrm{C}_{3}=$ Dalam Tahun

$\mathrm{C}_{4}=$ Dalam Juta

$\mathrm{C}_{5}=$ Dalam Tahun

Nilai terbesar akan terpilih menjadi alternatif atau asuransi jiwa dengan nilai tertinggi terpilih sebagai alternatif terbaik. Dan untuk memilih asuransi jiwa lainya juga dilakukan proses perengkingan seperti langkah diatas

Pada tahap ini, yang harus dilakukan adalah menentukan tujuan yang ingin dicapai dan menentukan kriteria-kriteria untuk seleksi.

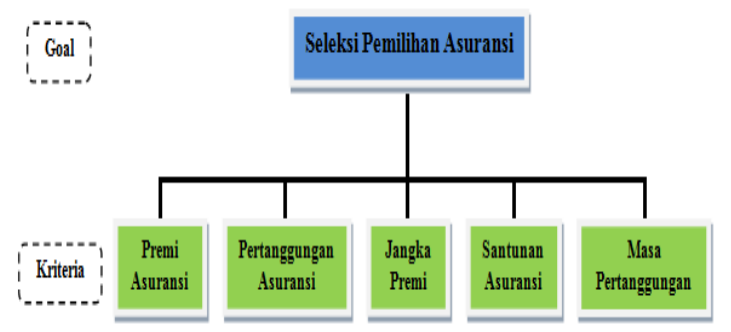

Gambar 1. Sistem hieraki pemiliham asuransi

Untuk menentukan prioritas digunakan metode perbandingan berpasangan (Pairwise Comparason) dengan 9 skala penilaian untuk setiap kriteria maupun setiap alternatif berdasarkan kriteria.

Tabel 3. Matriks 
Imam Sunoto, Arif Susanto: Sistem pendukung keputusan pemilihan asuransi jiwa menggunakan metode analytic hierarchy process dengan criterium decision plus

Jurnal Teknologi 9 (1) pp 7- 12 (c) 2017

\begin{tabular}{|c|c|c|c|c|}
\hline Level & $\mathbb{E}$ Matriks & Dimensi & $\mathbb{E}$ Sel & $\mathbb{E}$ Pertanyaan \\
\hline Goal & 0 & - & - & - \\
\hline Kreteria & 1 & $5 \times 5$ & $1(5 \times 5)=25$ & $1(5 \times 5-5) / 2=10$ \\
\hline Alternatif & 5 & $5 \times 5$ & $5(5 \times 5)=125$ & $5(5 \times 5-5) / 2=50$ \\
\hline & & & Total Pertanyaan & $10+50=60$ \\
\hline
\end{tabular}

\section{Penggunaan Proses Hierarki Analitik}

Membandingkan tingkat kepentingan elemen berdasarkan Kriteria

Tabel 4. Pair Comparation matrix

\begin{tabular}{|l|c|c|c|c|c|}
\hline Kriteria & $\begin{array}{c}\text { Premi } \\
\text { Asuran } \\
\text { si }\end{array}$ & $\begin{array}{c}\text { Pertangg } \\
\text { ungan } \\
\text { Asuran } \\
\text { si }\end{array}$ & $\begin{array}{c}\text { Jangka } \\
\text { Premi }\end{array}$ & $\begin{array}{c}\text { San } \\
\text { tunan } \\
\text { Asuran } \\
\text { si }\end{array}$ & $\begin{array}{c}\text { Masa } \\
\text { Pertangg } \\
\text { ungan }\end{array}$ \\
\hline $\begin{array}{l}\text { Premi } \\
\text { Asuransi }\end{array}$ & 1 & 3 & 4 & 3 & 2 \\
\hline $\begin{array}{l}\text { Pertangg } \\
\text { ungan } \\
\text { Asuransi }\end{array}$ & $1 / 3$ & 1 & 2 & 2 & 3 \\
\hline $\begin{array}{l}\text { Jangka } \\
\text { Premi }\end{array}$ & $1 / 4$ & $1 / 2$ & 1 & 2 & 3 \\
\hline $\begin{array}{l}\text { Santu } \\
\text { nan } \\
\text { Asuransi }\end{array}$ & $1 / 3$ & $1 / 2$ & $1 / 2$ & 1 & 3 \\
\hline $\begin{array}{l}\text { Masa } \\
\text { Pertang } \\
\text { gungan }\end{array}$ & $1 / 2$ & $1 / 3$ & $1 / 3$ & $1 / 3$ & 1 \\
\hline
\end{tabular}

\section{Penyelesaian kasus AHP}

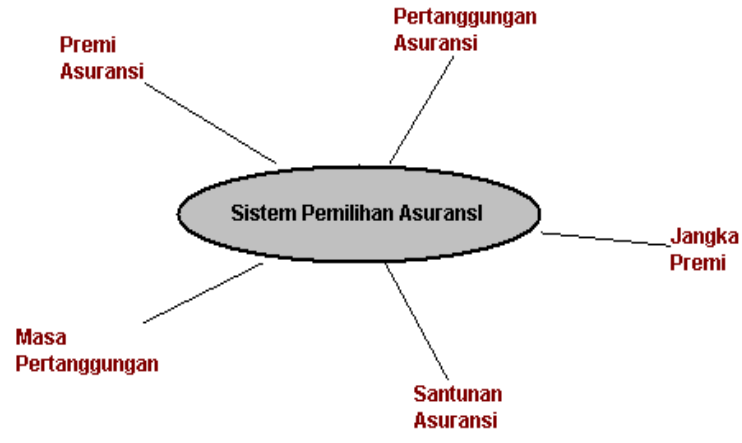

Gambar 2. Brainstorm seleksi pemilihan asuransi

\section{Struktur Hirarki}

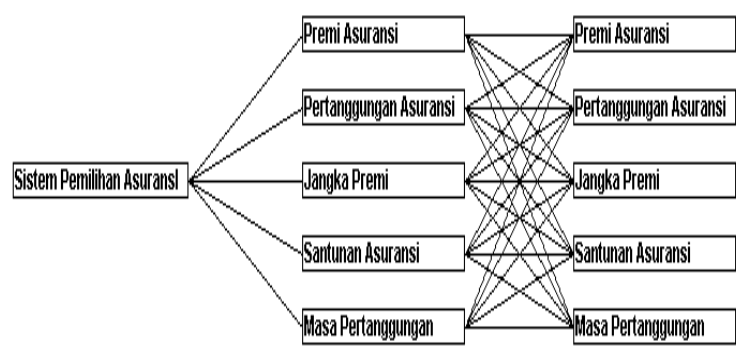

Gambar 3. Hierarki seleksi pemilihan asuransi

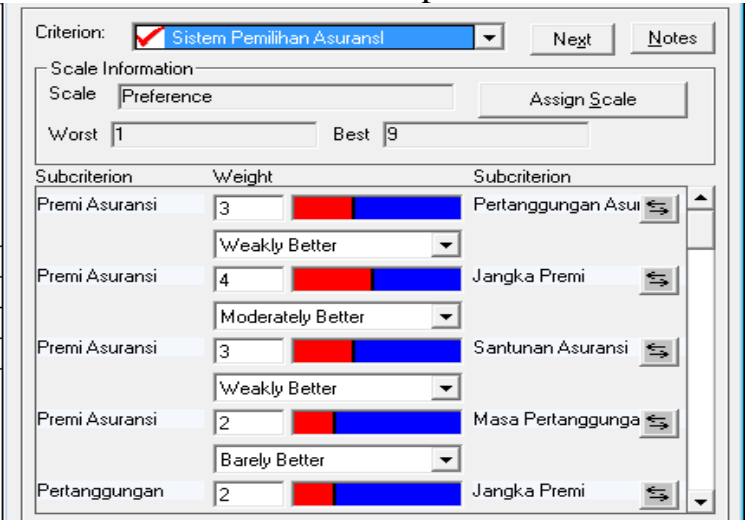

Gambar 4. Perbandingan Tingkat Kepentingan Elemen Faktor

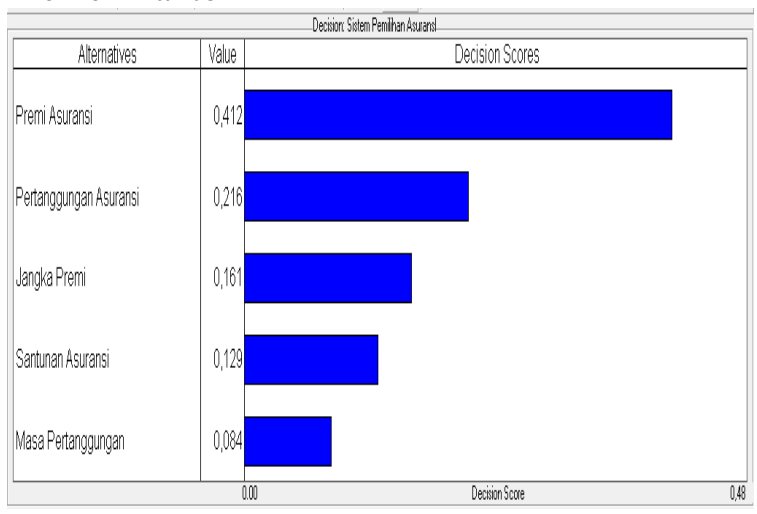

Gambar 5. Hasil decision score

\section{SIMPULAN DAN SARAN}

Dalam seleksi pemilihan asuransi ini, analisa yang dilakukan menggunakan metode proses analisa bertingkat dengan struktur hierarki. Hasil analisa, menunjukkan bahwa urutan alternatif yang dapat dipertimbangkan adalah: Premi Asuransi, Pertanggungan Asuransi, Jangka Premi, Santunan Asuransi, dan terakhir adalah Masa Pertanggungan.

Urutan Kriteria diperoleh dengan membandingkan 5 alternatif berdasarkan kriteria. Hasil perhitungan menunjukkan bahwa kriteria yang paling berpengaruh adalah faktor Premi Asuransi dan yang paling sedikit pengaruhnya adalah faktor Masa Pertanggungan. 


\section{DAFTAR PUSTAKA}

Efraim Turban, Jay E. Aronson, Ting-Peng Liang. 2005. Decision Support System And Intelligent System-7th Ed. Pearson Education, Inc. Upper Saddle River, New Jersey, 2005.

Kusrini. 2007. Konsep dan Aplikasi Sistem Pendukung Keputusan. Penerbit Andi Offset, Yogyakarta, Edisi 1.

Marimin, Nurul. 2011. Aplikasi Teknik Pengambilan Keputusan dalam Manajemen Rantai Pasok, IPB Press, Bogor.

Saaty, L. Thomas. 1993. Pengambilan Keputusan Bagi Para Pemimpin: Proses Hierarki Analitik Untuk Pengambilan Keputusan Dalam Situasi Yang Kompleks. Seri Manajemen No.134. Cetakan kedua. PT. Gramedia. Jakarta. 